\title{
Editorial
}

\section{Improving Outcomes with Lung Cancer Surgery: Selective Referral or Quality Improvement?}

\author{
John D. Birkmeyer, MD \\ Department of Surgery, Michigan Surgical Collaborative for Outcomes Research and Evaluation (M-SCORE), University \\ of Michigan, 211 N. 4th Avenue, Ann Arbor, MI 48104, USA
}

The first evidence that procedure volume and other hospital attributes contribute to the outcomes of major surgery recently turned 50 years old. ${ }^{1}$ In cancer surgery, the relative importance of hospital factors varies widely according to which procedure and which outcome is being addressed. ${ }^{2}$ Nonetheless, a large body of literature documents the importance of hospital procedure volume as a determinant of both operative mortality and, more recently, late survival after a wide range of cancer procedures. ${ }^{3,4}$ Although this literature is less consistent, teaching hospitals may also have better outcomes for some procedures above and beyond that corresponding to their higher volumes.

In this context, results from the analysis by Cheung et al. herein are not surprising. ${ }^{5}$ Among patients undergoing surgery for lung cancer in Florida, 30- and 90-day mortality rates at teaching hospitals and high-volume centers were only half as high as at other hospitals. Despite comparable case mix among the hospital groups, median survival after surgery at teaching hospitals and high-volume hospitals was almost 6 months greater. Given limitations in their data, the study does not provide insights regarding potential mechanisms underlying disparities in hospital outcomes; for example, the study did not explore the role of surgeon volumes and specialty, factors previously found to mediate hospital volumeoutcome relationships in lung cancer surgery. ${ }^{6}$ It also did not examine differences in process of care that could explain better outcomes at teaching hospitals

Published online November 7, 2008.

Address correspondence and reprint requests to: John D. Birkmeyer, MD; E-mail: jbirkmey@umich.edu

Published by Springer Science+Business Media, LLC $\odot 2008$ The Society of Surgical Oncology, Inc. and high-volume centers, such as greater adoption of new technology, including video-assisted resection techniques. Regardless of underlying mechanisms, however, there seems to be little doubt that lung cancer patients can improve their odds considerably by choosing the right hospital for surgery.

Cheung et al. join a chorus of advocates for concentration of complex cancer procedures in selected facilities. This goal might be achieved by patient education and public reporting of hospital volume, teaching status, and, where available, outcomes. Selective contracting by payers is a more direct and likely more effective approach to effecting evidencebased referral for complex surgical care; for example, the Leapfrog Group, a large purchaser coalition, has an evidence-based referral program for several complex procedures, including pancreatectomy and esophagectomy, based primarily on minimum volume standards. ${ }^{7}$ Private payers nationwide are increasingly implementing centers-of-excellence programs for cardiac surgery and bariatric surgery, models that could be readily extended to cancer care.

As an approach to improving outcomes of cancer surgery, selective referral based on simple structural measures (e.g., volume, teaching status) has several advantages. Such measures can be obtained readily and inexpensively. They tend to be relatively stable quality indicators. Volume in particular seems to be as useful in forecasting future hospital outcomes as it is in describing historical performance. ${ }^{8}$ Finally, if targeted at relatively infrequent procedures and if the bar is not set too high, selective referral would be practical from a policy perspective; for example, access and patient travel time for pancreatectomy and esophagectomy would be affected negligibly if every one of the almost 1,000 very low-volume hospitals 
carrying out these procedures in the USA were prohibited from performing them. ${ }^{9}$

However, as a tool for improving patient outcomes, selective referral has important limitations; for example, selective referral policies for more common cancer procedures could have significant impact on capacity at teaching hospitals and highvolume centers. It could also weaken relationships between the surgical and nonsurgical components of multidisciplinary cancer care and hinder coordination of care, including adjuvant therapy. Moreover, selective referral would not eliminate variation in outcomes across hospitals. Volume, teaching status, and other structural variables identify groups of hospitals with superior outcomes, but are unreliable in predicting performance for individual centers. Some high-volume hospitals have poor outcomes, while some low-volume centers may have excellent results. Thus, selective referral initiatives would paradoxically result in the transfer of some patients to hospitals with worse outcomes.

For this reason, selective referral should be implemented thoughtfully. First, it should target uncommon, high procedures for which outcomes vary widely across hospitals (e.g., pancreatectomy and esophagectomy), but not more ubiquitous procedures associated with little performance variation (e.g., colectomy). Where lung resection falls on this spectrum is a matter of debate. Second, the bar should not be set too high. In contrast to those simply targeting very low-volume hospitals, policies aimed at restricting surgery to a small number of teaching hospitals or high-volume centers would be impractical for large parts of the country. ${ }^{10}$ Finally, selective referral should be based on measures which optimally discriminate performance among providers. Composite measures that account for both structural variables and outcomes likely perform better in this regard than individual quality indicators. ${ }^{11}$

Although pressures to concentrate high-risk surgical procedures in selected facilities are not likely to abate, we should continue to develop strategies for improving the quality of cancer surgery in all settings. Success in this regard will require broader dissemination of quality measurement and feedback tools, such as the American College of Surgeons' National Surgical Quality Improvement Program. ${ }^{12}$ A better understanding of mechanisms underlying variation in outcomes across hospitals would also be invaluable.
Which types of complications explain excess deaths at some hospitals? Are they medical (e.g., pulmonary embolism) or surgical (anastomotic leaks) in nature? Are there measurable differences in processes of care between hospitals with good and bad outcomes? Answers to such questions will be essential for optimizing the safety of high-risk cancer surgery.

\section{ACKNOWLEDGEMENT}

This work was supported in part by the National Cancer Institute (2 R01 CA098481-05A1). This manuscript is subject to the NIH Public Access Policy.

\section{REFERENCES}

1. Lee JAH, Morrison SL, Morris JN. Fatality from three common surgical conditions in teaching and non-teaching hospitals. Lancet 1957; 2:785-90.

2. Luft HS, Bunker JP, Enthoven AC. Should operations be regionalized? The empirical relation between surgical volume and mortality. $N$ Engl J Med 1979; 301:1364-9.

3. Begg CB, Cramer LD, Hoskins WJ, et al. Impact of hospital volume on operative mortality for major cancer surgery. JAMA 1998; 280:1747-51.

4. Birkmeyer JD, Sun Y, Wong SL, et al. Hospital volume and late survival after cancer surgery. Ann Surg 2007; 247:777-83.

5. Cheung MC, Hamilton K, Sherman R, et al. Impact of teaching facility status and high volume centers on outcomes for lung cancer resection: an examination of 13,469 surgical patients. Ann Surg Oncol (herein).

6. Goodney PP, Lucas FL, Siewers AS, et al. Surgeon specialty and operative mortality with lung resection. Ann Surg 2005; 241:179-84.

7. http://www.leapfroggroup.org/media/file/Leapfrog-EvidenceBased_Hospital_Referral_Fact_Sheet.pdf (last accessed July 17, 2008).

8. Birkmeyer JD, Dimick JB, Staiger DO. Operative mortality and procedure volume as predictors of future hospital performance. Ann Surg 2006; 243:411-7.

9. Birkmeyer JD, Siewers AS, Marth NJ, et al. Regionalization of high-risk surgery and implications for patient travel times. JAMA 2003; 290:2703-8.

10. Dimick JB, Finlayson SR, Birkmeyer JD. Regional availability of high-volume hospitals for major surgery. Health Aff (Millwood). 2004;Suppl Web Exclusives:VAR45-53.

11. O'Brien SM, Shahian DM, DeLong ER, et al. Quality measurement in adult cardiac surgery: part 2-Statistical considerations in composite measure scoring and provider rating. Ann Thorac Surg 2007; 83:S13-26.

12. Fink AS, Campbell DA Jr, Mentzer RM Jr, et al. The National Surgical Quality Improvement Program in non-veterans administration hospitals: initial demonstration of feasibility. Ann Surg 2002; 236:344-53. 